\title{
QUANTIFICAÇÃO DA CONTAMINAÇ̃̃O BIOLÓGICA POR ESPÉCIES ARBÓREAS EXÓTICAS EM UM FRAGMENTO DE FLORESTA OMBRÓFILA MISTA EM LAGES - SC
}

\author{
QUANTIFICATION OF BIOLOGICAL CONTAMINATION BY EXOTIC TREE SPECIES IN AN \\ ARAUCARIA FOREST FRAGMENT IN LAGES, SANTA CATARINA STATE
}

\author{
Fábio Rodrigues Spiazzi ${ }^{1}$ Ana Carolina da Silva ${ }^{2}$ Pedro Higuchi ${ }^{3}$ Marcelo Negrini ${ }^{3}$ \\ André Luiz Guidini $^{3}$ Tiago de Souza Ferreira ${ }^{3}$ Manoela Drews de Aguiar ${ }^{3}$ Amanda da Silva Nunes ${ }^{4}$ \\ Aline Pereira Cruz ${ }^{5}$ Vanessa Fátima Soboleski ${ }^{4}$
}

\begin{abstract}
RESUMO
O presente trabalho objetivou avaliar a contaminação biológica ao longo do tempo em uma comunidade arbórea em estágio sucessional avançado/tardio da Floresta Ombrófila Mista Montana, adjacente a um plantio de Pinus taeda L. em Lages - SC. Para isso, foram alocadas 25 parcelas de 20 x $20 \mathrm{~m}$, distribuídas em cinco transeções de cinco parcelas cada, alocadas perpendiculares à borda de contato com o plantio de pinus. Em cada parcela foram mensurados (DAP $\geq 5 \mathrm{~cm}$, medido a $1,30 \mathrm{~m}$ do solo), coletados e identificados todos os indivíduos arbóreos vivos. Quatro anos após o primeiro inventário, os mesmos indivíduos foram novamente inventariados, quantificando-se os indivíduos mortos, sobreviventes e adicionando os recrutas. Para os dois períodos foram calculados os descritores fitossociológicos, quantificados os indicadores de invasão para a comunidade como um todo e grupos ecológicos e calculadas as taxas demográficas. No primeiro ano foram amostradas 73 espécies e no segundo 74 espécies, dentro das quais, duas foram exóticas: Pinus taeda e Ligustrum lucidum W.T. Aiton. Ambas tiveram baixos valores dos indicadores de invasão para a comunidade nos dois anos, no entanto, com aumento da participação de Pinus taeda entre as espécies pioneiras ao longo do tempo. Os resultados das taxas demográficas sugerem que, para os diferentes grupos ecológicos, o processo de invasão encontra-se em fases distintas. Conclui-se que o grupo das espécies pioneiras foi o componente mais afetado pela invasão biológica, o que reforça a necessidade de análise, considerando os diferentes grupos ecológicos.
\end{abstract}

Palavras-chave: fragmentos florestais; dinâmica florestal; estudo temporal.

\begin{abstract}
The present study aimed to evaluate the biological contamination over time in a tree community of Montane Araucaria forest, in advanced successional stage, adjacent to a Pinus taeda L. plantation, in Lages, SC state. For this sake, a total of, $20 \times 20 \mathrm{~m}, 25$ plots, distributed in five transects with five plots each, were allocated perpendicular to the edge in contact with the pinus plantation. In each plot, all living trees were measured (cbh $\geq 5 \mathrm{~cm}$, measured at $1.30 \mathrm{~m}$ above soil level), collected and identified. Four years after the first

1 Engenheiro Florestal, MSc., Departamento de Engenharia Florestal, Universidade do Estado de Santa Catarina. Av. Luiz de Camões, 2090, CEP 88520-000, Lages (SC), Brasil. maxplus2007@yahoo.com.br / engfmarcelonegrini@ hotmail.com/andrelg85@yahoo.com.br/tiagoferreira@florestal.eng.br/manoo_aguiar@hotmail.com

2 Engenheira Florestal, Dr ${ }^{\mathrm{a}}$., Professora do Departamento de Engenharia Florestal, Universidade do Estado de Santa Catarina. Av. Luiz de Camões, 2090, CEP 88520-000, Lages (SC), Brasil. carol_sil4@yahoo.com.br

3 Engenheiro Florestal, Dr., Professor do Departamento de Engenharia Florestal, Universidade do Estado de Santa Catarina. Av. Luiz de Camões, 2090, CEP 88520-000, Lages (SC), Brasil. higuchip@gmai.com de Camões, 2090, CEP 88520-000, Lages (SC), Brasil. manoo_aguiar@hotmail.com

4 Engenheira Florestal, Departamento de Engenharia Florestal, Universidade do Estado de Santa Catarina. Av. Luiz de Camões, 2090, CEP 88520-000, Lages (SC), Brasil. amandaeng.f@gmail.com/ vanessasoboleski@hotmail.com

5 Bióloga, Departamento de Engenharia Florestal, Universidade do Estado de Santa Catarina. Av. Luiz de Camões, 2090, CEP 88520-000, Lages (SC), Brasil. a.line_cruz@yahoo.com.br
\end{abstract}

Recebido para publicação em 8/11/2012 e aceito em 11/11/2015 
inventory, the same individuals were re-inventoried, the dead individuals and survivor quantified and recruits added. For the two evaluated years, phytosociological descriptors were calculated, indicators of biological invasion quantified for all community as well as for ecological groups and the demographic rates determined. A total of 73 and 74 species were sampled in the first and second years, among of them two exotic species: Pinus taeda and Ligustrum lucidum W.T. Aiton. Both species showed low values of the invasion indicators, but with an increment in the participation of Pinus taeda among pioneer species over time. Results of demographic rates suggest that, for different ecological groups, the invasion process is in distinct stages. We conclude that the pioneer species was the most affected component by biological invasion, which reinforces the need for analysis considering the different ecological groups.

Keywords: forest fragment; forest dynamics; temporal study.

\section{INTRODUÇÃO}

Contaminação biológica é o processo, geralmente causado pelo homem, de introdução de espécies em um ecossistema do qual não fazem parte e de adaptação destas, provocando mudanças no funcionamento desse ecossistema (SANTANA; ENCINAS, 2008). Poucos habitats têm permanecido imunes ou livres de ações humanas que introduzem espécies exóticas (MACK et al., 2000). As espécies introduzidas, por não terem coevoluído com as espécies nativas, muitas vezes não possuem um predador natural, e, por isso, podem apresentar maior vantagem competitiva para se estabelecerem, reproduzirem e se desenvolverem, tornando-se espécies invasoras. Segundo Zanchetta e Diniz (2006), entre os principais impactos provocados pelas espécies invasoras, estão aqueles ligados aos processos biológicos essenciais, como as alterações na ciclagem de nutrientes, na produtividade vegetal, na cadeia trófica, na estrutura das comunidades, na diversidade de espécies, dentre outros.

Dentre as características que permitem que as espécies exóticas se tornem potenciais invasoras, Santana e Encinas (2008), Genovesi (2005) e Westbrooks (1998) destacam: alto poder de crescimento relativo, alta produção de sementes de fácil dispersão, alta longevidade das sementes no solo, alta taxa de germinação dessas sementes, maturação precoce das plantas já estabelecidas, floração e frutificação mais prolongadas, alto potencial reprodutivo por brotação, pioneirismo, alelopatia e ausência de inimigos naturais. Entre as espécies que possuem algumas dessas características citadas estão as do gênero Pinus. Segundo Zanchetta e Diniz (2006), espécies desse gênero se destacam entre as espécies com alto potencial de invasão, sendo detectadas em pelo menos 35 Unidades de Conservação das regiões Sul e Sudeste do Brasil. Esta invasão ocorre predominantemente em sistemas vegetacionais abertos com predomínio de gramíneas e arbustos ou árvores esparsas, assim como em áreas de formações florestais onde tenha havido desmatamento (FALLEIROS et al., 2011; ZILLER; GALVÃO, 2002). Moretto e Nodari (2009) relataram que espécies de Pinus são uma ameaça para os ecossistemas naturais da região de Lages - SC, onde essas espécies são amplamente cultivadas, sendo as duas espécies mais plantadas o Pinus taeda L. e o Pinus elliottii Engelm. Zanchetta e Diniz (2006) destacam que essas duas espécies pertencem ao gênero com potencial mais invasivo em campos abertos no Brasil.

O Parque Municipal de Lages, denominado Parque Natural Municipal João José Theodoro da Costa Neto (PARNAMUL), possui um remanescente de Floresta Ombrófila Mista Montana que se encontra adjacente a um plantio de Pinus taeda. Com o intuito de verificar a influência desse plantio de pinus sobre a vegetação natural arbórea do parque, o presente estudo objetivou avaliar a contaminação biológica ao longo do tempo em uma comunidade arbórea em estágio sucessional avançado/tardio da Floresta Ombrófila Mista Montana, adjacente a um plantio de Pinus taeda. A quantificação da intensidade na invasão biológica pode ser utilizada como um parâmetro no planejamento de ações futuras visando práticas mitigadoras nas áreas naturais em que se observam espécies com comportamento invasor.

\section{MATERIAL E MÉTODOS}

Foi realizado o levantamento fitossociológico de um trecho da área do Parque Natural Municipal João José Theodoro da Costa Neto (PARNAMUL) localizado no município de Lages - SC. O PARNAMUL, com aproximadamente 204 ha, encontra-se em contato com um plantio de Pinus taeda, com cerca de 15 
anos de idade e área de $60 \mathrm{ha}$, separados apenas por uma faixa de aceiro de aproximadamente $3 \mathrm{~m}$ de largura (Figura 1 A-D).

Lages está localizada na latitude $27^{\circ} 48^{\prime} 58^{\prime}$ "Sul e longitude $50^{\circ} 19^{\prime} 30^{\prime \prime}$ Oeste, no Planalto Sul Catarinense, com altitude em torno de $916 \mathrm{~m}$. O clima predominante na região é $\mathrm{Cfb}$, de acordo com a classificação de Köppen, sendo a precipitação anual média de 1.479,48 mm, com chuvas bem distribuídas durante o ano, e temperatura anual média de $16^{\circ} \mathrm{C}$ (BRASIL, 1992). O município de Lages está inserido na Bacia Hidrográfica do Rio Canoas e do Rio Pelotas, com topografia, em sua maior parte, suave ondulada a ondulada. Segundo a classificação do IBGE (2012), a vegetação florestal de Lages é classificada como Floresta Ombrófila Mista Montana (FOM-Montana). O PARNAMUL possui vegetação florestal integralmente protegida e em estádio intermediário a avançado de sucessão, conforme observado por Dalla Rosa et al. (2015).

Para a amostragem da vegetação arbórea, foram alocadas, em 2011 por Guidini et al. (2014), 25 parcelas de $400 \mathrm{~m}^{2}(20 \times 20 \mathrm{~m}$, totalizando 1 ha amostrado), distribuídas em cinco transectos de cinco parcelas cada, alocados perpendiculares à borda de contato com o plantio de pinus (Figura 1A). As parcelas foram distribuídas de forma a contemplar a heterogeneidade ambiental existente na área, como aquelas associadas às variações de borda/interior, relevo e aos estágios sucessionais da floresta, sendo que alguns trechos possuíam áreas de clareiras, o que é esperado em uma floresta natural. Assim, cada parcela no transecto possuía uma distância da borda, sendo essa de $0 \mathrm{~m}$ na primeira parcela, $20 \mathrm{~m}$ na segunda, $40 \mathrm{~m}$ na terceira, $60 \mathrm{~m}$ na quarta e $80 \mathrm{~m}$ na última parcela. Em cada parcela foram medidos (circunferência a altura do peito - CAP), coletados, identificados e marcados com plaquetas de alumínio todos os indivíduos arbóreos vivos que apresentaram diâmetro igual ou superior a $5 \mathrm{~cm}$, medido a 1,30 m do solo (DAP). Indivíduos com

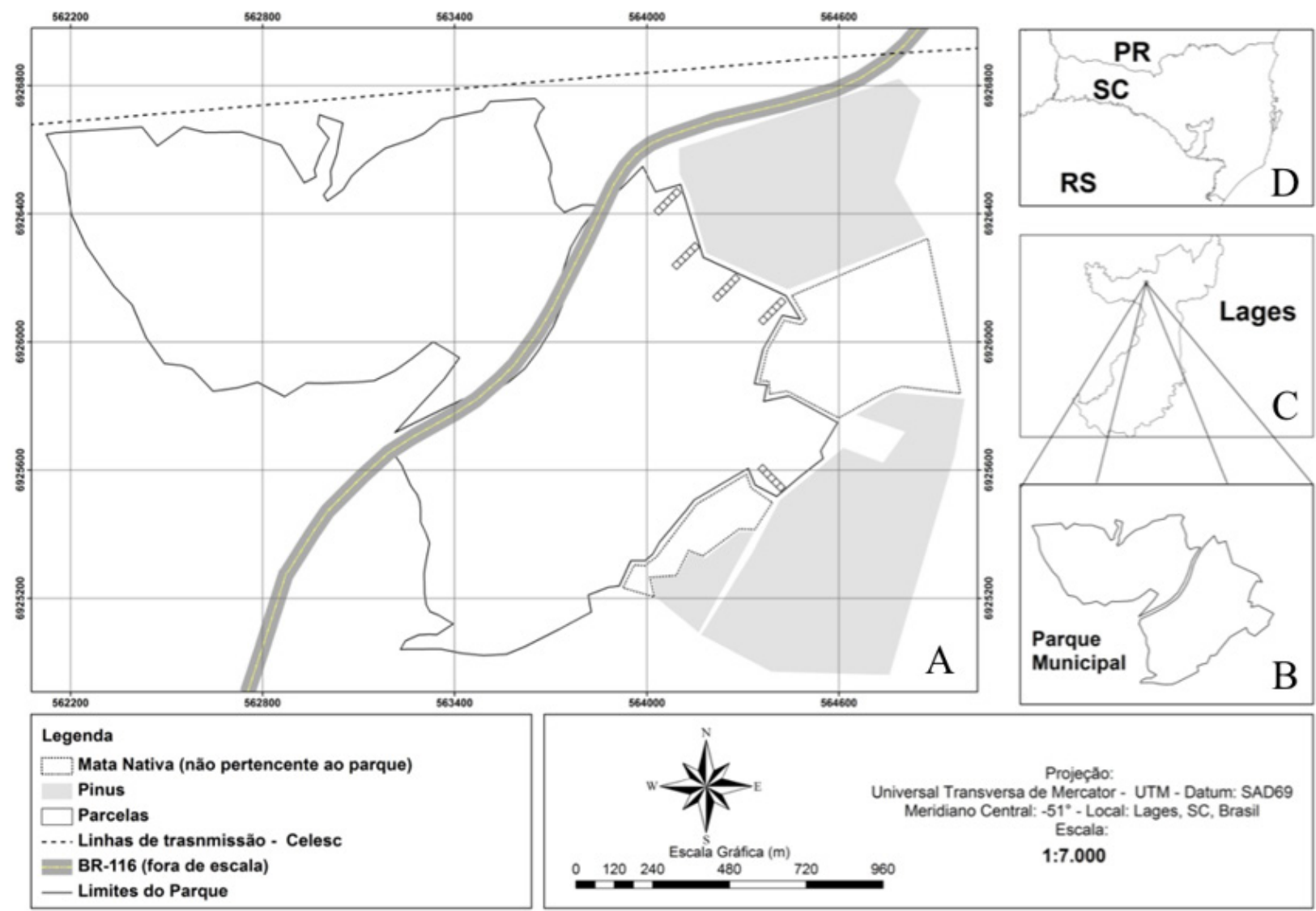

FIGURA 1: Mapa de localização das parcelas alocadas (A), no Parque Natural Municipal João José Theodoro da Costa Neto (B), no município de Lages (C), em Santa Catarina (D).

FIGURE 1: Location map of plots (A) allocated in Parque Natural Municipal João José Theodoro da Costa Neto (B), in the municipality of Lages (C), Santa Catarina state (D). 
troncos múltiplos foram medidos quando a raiz da soma dos quadrados dos DAP foi maior ou igual a $5 \mathrm{~cm}$. As identificações foram realizadas por meio de consultas a especialistas e literatura especializada (REITZ, 1970; SOBRAL et al., 2006). As espécies foram classificadas nas famílias de acordo com o sistema APG III (ANGIOSPERM PHYLOGENY GROUP, 2009).

Quatro anos após o primeiro inventário, em 2015, os indivíduos foram reiventariados, sendo que os sobreviventes foram novamente mensurados (CAP) e os mortos foram quantificados. Indivíduos dentro das parcelas que atingiam o diâmetro mínimo de inclusão de $5 \mathrm{~cm}$ de DAP eram considerados recrutas e estes foram identificados, mensurados (CAP) e marcados em plaquetas de alumínio, seguindo a mesma metodologia do primeiro ano de inventário.

As espécies foram ordenadas, de forma decrescente, por meio de seu valor de importância (VI) em 2011, calculado pela média dos valores relativos de densidade, frequência e dominância relativa nesse ano, sendo calculados também os valores de VI para 2015, calculados da mesma forma, conforme MuellerDombois e Ellenberg (1974).

Para a quantificação das mudanças temporais na comunidade e populações arbóreas durante o período de 2011 e 2015, foram calculadas as taxas de dinâmica, expressas em $\%$. ano ${ }^{-1}$ : taxas de mortalidade e recrutamento e taxas de ganho e perda em área basal. Estas foram calculas conforme os modelos algébricos (LIEBERMAN et al., 1985; PRIMACK et al., 1985; SHEIL; MAY, 1996): $M=\left(1-\left(\left(N_{\mathrm{o}}-m\right) / N_{\mathrm{o}}\right)^{1 / \mathrm{t}}\right) \times 100$; $R=\left(1-\left(1-r / N_{t}\right)^{1 / t}\right) \times 100 ; P=\left(1-\left[\left(A B_{\mathrm{o}}-(A B \mathrm{~m}+A B \mathrm{~d})\right) / A B_{\mathrm{o}}\right)^{1 / t}\right) \times 100$, e $G=(1-[1-(A B \mathrm{r}+A B \mathrm{~g}) /$ $\left.A B \mathrm{t})^{1 / \mathrm{t}}\right) \times 100$. Em que: $\mathrm{M}=$ taxa de mortalidade anual; $\mathrm{R}=$ taxa de recrutamento anual; $\mathrm{P}=$ taxa de perda em área basal anual; $\mathrm{G}=$ taxa de ganho em área basal anual; $\mathrm{t}=$ intervalo de tempo entre inventários; No = número inicial de árvores; $\mathrm{Nt}=$ número final de árvores depois de $\mathrm{t} ; \mathrm{m}=$ número de árvores mortas; $\mathrm{r}$ $=$ número de árvores recrutadas; $\mathrm{ABo}=$ área basal inicial; $\mathrm{ABt}=$ área basal final depois de $\mathrm{t} ; \mathrm{ABm}=$ área basal das árvores mortas; $\mathrm{ABd}=$ perda em área basal (redução diamétrica e perda parcial de troncos); $\mathrm{ABr}$ = área basal de árvores recrutadas; $\mathrm{ABg}=$ ganho em área basal (crescimento das árvores). Também foram calculadas as diferenças em número de indivíduos $\left(\mathrm{D}_{\mathrm{NI}}\right)$ e em área basal $\left(\mathrm{D}_{\mathrm{AB}}\right)$ de cada população entre os períodos de inventário.

Para quantificar o nível de invasão biológica, foram utilizados os indicadores apresentados por Catford et al. (2012), considerando valores absolutos de riqueza, abundância e área basal do conjunto de espécies invasoras, bem como seus respectivos valores relativos em relação à comunidade. Os indicadores foram calculados para a comunidade como um todo, nos dois períodos de tempo, e por grupos ecológicos das espécies. No caso dos cálculos por grupos ecológicos, utilizou-se somente a(s) espécie(s) exótica(s) invasora(s) pertencente(s) ao grupo. Foram utilizadas as classes definidas por Swaine e Whitmore (1988), que dividiram as espécies em dois grandes grupos, pioneiras, sendo aquelas que necessitam de luz para germinar e completar todo o ciclo de vida, e clímax, sendo aquelas que frequentemente ocorrem no subbosque florestal. Ainda, de acordo com a adaptação sugerida por Oliveira Filho et al. (1994), o grupo das climácicas foi subdivido em função da exigência lumínica das espécies em "clímax exigentes em luz", sendo aquelas que precisam de luz para completar o ciclo de vida, e "clímax tolerantes ao sombreamento", sendo aquelas que germinam em condição de sub-bosque e podem completar todo o ciclo de vida nestas condições. Para a classificação das espécies amostradas nos grupos ecológicos de regeneração, foram utilizadas a literatura existente (LINDENMAIER; BUDKE, 2006; LEYSER et al., 2012; SILVA et al., 2013) e as observações no campo.

Foram calculadas, para a comunidade e cada grupo ecológico contaminado por espécies invasoras, as taxas de mortalidade, recrutamento, perda em área basal e ganho em área basal, considerando o conjunto das espécies nativas e o das espécies exóticas, conforme modelos descritos acima.

\section{RESULTADOS E DISCUSSÃO}

\section{Caracterização da comunidade}

Em 1 ha, foram amostradas 73 espécies em 2011 e 74 em 2015 (Tabela 1), indicando estabilidade do número de espécies entre os anos. O aumento de apenas uma espécie se deu pela saída de Citronella paniculata, Solanum mauritianum e Solanum variabile da comunidade em 2015, todas representadas 
TABELA 1: Espécies arbóreas encontradas nas 25 parcelas de um fragmento de Floresta Ombrófila Mista, próximo a plantios comerciais de Pinus taeda em Lages - SC, e seus respectivos descritores fitossociológicos e taxas demográficas.

TABLE 1: Phytosociological descriptors and demographic rates of trees species in an Araucaria Forest fragment near Pinus taeda commercial plantations, in Lages, SC state.

\begin{tabular}{|c|c|c|c|c|c|c|c|c|c|}
\hline Espécies & $\mathrm{VI}_{2011}$ & $\mathrm{VI}_{2015}$ & GE & $\mathrm{T}_{\text {mort }}$ & $\mathrm{T}_{\mathrm{rec}}$ & $\mathrm{D}_{\mathrm{NI}}$ & $\mathrm{T}_{\text {per }}$ & $\mathrm{T}_{\text {gan }}$ & $\mathrm{D}_{\mathrm{AB}}$ \\
\hline Casearia decandra Jacq. & 8,73 & 9,35 & CTS & 2,10 & 3,99 & 13 & 1,56 & 3,88 & 0,1153 \\
\hline Myrcia hatschbachii D.Legrand & 7,15 & 7,12 & CTS & 2,32 & 2,32 & - & 2,97 & 1,65 & $-0,1307$ \\
\hline Calyptranthes concinna DC. & 5,84 & 5,73 & CTS & 2,67 & 0,35 & -7 & 1,69 & 2,22 & 0,0366 \\
\hline Myrcia splendens (Sw.) DC. & 5,65 & 4,72 & CEL & 4,52 & - & -12 & 5,80 & 1,28 & $-0,2668$ \\
\hline Araucaria angustifolia (Bertol.) Kuntze & 4,94 & 5,06 & CEL & 3,02 & 1,06 & -2 & 2,42 & 2,11 & $-0,0321$ \\
\hline Matayba elaeagnoides Radlk. & 4,43 & 5,23 & CEL & 1,16 & 5,20 & 4 & 0,20 & 1,65 & 0,1431 \\
\hline Lithrea brasiliensis Marchand & 4,28 & 3,70 & CEL & 4,96 & 0,79 & -6 & 6,63 & 1,30 & $-0,2813$ \\
\hline Cupania vernalis Cambess. & 4,08 & 4,16 & CEL & 1,50 & 1,50 & - & 1,02 & 1,05 & 0,0016 \\
\hline Banara tomentosa $\mathrm{Clos}$ & 3,67 & 3,89 & CEL & 3,36 & 3,36 & - & 3,58 & 1,67 & $-0,0662$ \\
\hline Cinnamodendron dinisii Schwacke & 2,97 & 2,64 & CEL & 2,43 & - & -3 & 3,91 & 1,66 & $-0,0423$ \\
\hline Casearia obliqua Spreng. & 2,89 & 2,58 & CEL & 5,15 & - & -4 & 5,55 & 1,69 & $-0,2066$ \\
\hline Dasyphyllum brasiliense (Spreng.) Cabrera & 2,62 & 2,48 & CEL & 5,43 & 2,90 & -1 & 3,51 & 0,73 & $-0,1424$ \\
\hline Sebastiania commersoniana (Baill.) L.B.Sm. \& Downs & 2,49 & 2,00 & CEL & 3,78 & 1,34 & -2 & 13,23 & 1,94 & $-0,3810$ \\
\hline Myrcia palustris DC. & 2,06 & 1,70 & CEL & 5,67 & 2,47 & -3 & 12,40 & 1,58 & $-0,1434$ \\
\hline Eugenia pyriformis Cambess. & 1,96 & 1,92 & CTS & 1,21 & - & -1 & 2,00 & 1,05 & $-0,0201$ \\
\hline Vernonanthura discolor (Spreng.) H.Rob. & 1,76 & 2,17 & $\mathrm{P}$ & 2,35 & 13,67 & 7 & 0,52 & 6,33 & 0,1345 \\
\hline Prunus myrtifolia (L.) Urb. & 1,48 & 1,38 & CEL & 3,51 & 3,51 & - & 2,84 & 1,75 & $-0,0162$ \\
\hline Myrcia guianensis (Aubl.) DC. & 1,42 & 1,00 & CEL & 12,61 & - & -5 & 13,08 & 0,63 & $-0,1381$ \\
\hline Nectandra megapotamica (Spreng.) Mez & 1,41 & 1,50 & CEL & 3,51 & 5,06 & 1 & 3,60 & 1,32 & $-0,0416$ \\
\hline Moquiniastrum polymorphum (Less.) G. Sancho & 1,28 & 0,93 & $P$ & 8,53 & - & -3 & 6,58 & 1,28 & $-0,0683$ \\
\hline Ocotea puberula (Rich.) Nees & 1,27 & 1,41 & CEL & - & 4,89 & 2 & - & 4,30 & 0,0563 \\
\hline Myrsine coriacea (Sw.) R.Br. ex Roem. \& Schult. & 1,23 & 1,59 & CEL & 4,89 & 11,99 & 4 & 5,77 & 3,31 & $-0,0420$ \\
\hline Ocotea pulchella (Nees \& Mart.) Mez & 1,20 & 1,28 & CEL & - & 2,35 & 1 & - & 4,35 & 0,0396 \\
\hline Ilex theezans Mart. ex Reissek & 1,17 & 1,15 & CEL & 1,98 & - & -1 & 0,65 & 1,32 & 0,0067 \\
\hline Erythroxylum deciduum A.St.-Hil. & 1,14 & 0,85 & CEL & 9,64 & - & -5 & 6,36 & 2,59 & $-0,0354$ \\
\hline Eugenia uniflora L. & 1,13 & 1,27 & CEL & - & 1,98 & 1 & - & 3,07 & 0,0216 \\
\hline Clethra scabra Pers. & 1,12 & 0,99 & $\mathrm{P}$ & 2,90 & - & -1 & 3,22 & 1,82 & $-0,0219$ \\
\hline Allophylus edulis (A.St.-Hil. et al.) Hieron. ex Niederl. & 1,10 & 0,97 & CEL & 2,15 & - & -1 & 4,62 & 2,60 & $-0,0116$ \\
\hline Myrsine umbellata Mart. & 1,07 & 1,05 & CEL & 3,28 & 3,28 & - & 3,73 & 1,94 & $-0,0107$ \\
\hline Dicksonia sellowiana Hook. & 1,06 & 1,10 & CTS & 5,43 & 5,43 & - & 8,03 & 3,87 & $-0,0509$ \\
\hline Eugenia uruguayensis Cambess. & 1,02 & 1,07 & CEL & - & 2,15 & 1 & 0,14 & 3,73 & 0,0157 \\
\hline Myrcia laruotteana Cambess. & 1,02 & 1,02 & CEL & 2,35 & 2,35 & - & 1,92 & 3,70 & 0,0072 \\
\hline Zanthoxylum rhoifolium Lam. & 1,02 & 1,09 & CEL & 8,53 & 10,68 & 1 & 13,95 & 4,85 & $-0,0439$ \\
\hline Campomanesia xanthocarpa (Mart.) O.Berg & 0,96 & 0,96 & CTS & - & - & - & 0,59 & 0,60 & 0,0001 \\
\hline Myrsine lorentziana (Mez) Arechav. & 0,94 & 0,81 & CEL & 4,46 & - & -1 & 2,35 & 1,17 & $-0,0083$ \\
\hline Roupala montana Aubl. & 0,82 & 0,83 & CEL & - & - & - & - & 0,87 & 0,0077 \\
\hline Jacaranda puberula Cham. & 0,75 & 0,57 & CEL & 6,94 & - & -2 & 7,01 & 1,43 & $-0,0222$ \\
\hline Sebastiania brasiliensis Spreng. & 0,68 & 0,68 & CEL & - & - & - & 0,28 & 0,47 & 0,0012 \\
\hline
\end{tabular}


TABELA 1: Continuação...

TABLE 1: Continued...

\begin{tabular}{|c|c|c|c|c|c|c|c|c|c|}
\hline Espécies & $\mathrm{VI}_{2011}$ & $\mathrm{VI}_{2015}$ & GE & $\mathrm{T}_{\text {mort }}$ & $\mathrm{T}_{\mathrm{rec}}$ & $\mathrm{D}_{\mathrm{NI}}$ & $\mathrm{T}_{\mathrm{per}}$ & $\mathrm{T}_{\text {gan }}$ & $\mathrm{D}_{\mathrm{AB}}$ \\
\hline Myrrhinium atropurpureum Schott & 0,65 & 0,65 & CEL & - & - & - & 0,10 & 1,75 & 0,0033 \\
\hline Sapium glandulosum (L.) Morong & 0,63 & 0,77 & CEL & - & 6,94 & 1 & - & 0,85 & 0,0078 \\
\hline Eugenia pluriflora DC. & 0,60 & 0,56 & CTS & 4,46 & - & -1 & 2,48 & 2,22 & $-0,0004$ \\
\hline Scutia buxifolia Reissek & 0,54 & 0,54 & CEL & - & - & - & - & 1,97 & 0,0038 \\
\hline Xylosma ciliatifolia (Clos) Eichler & 0,54 & 0,54 & CEL & - & - & - & 0,08 & 0,08 & - \\
\hline Allophylus guaraniticus (A.St.-Hil.) Radlk. & 0,53 & 0,53 & CEL & - & - & - & 1,97 & 0,08 & $-0,0062$ \\
\hline Maytenus dasyclada Mart. & 0,53 & 0,40 & CTS & 6,94 & - & -1 & 3,42 & 0,79 & $-0,0032$ \\
\hline Drimys brasiliensis Miers & 0,47 & 0,50 & CEL & 5,43 & 9,64 & 1 & 8,08 & 9,27 & 0,0016 \\
\hline Annona rugulosa (Schltdl.) H.Rainer & 0,46 & 0,32 & CEL & 5,43 & - & -1 & 10,01 & 0,73 & 0,0060 \\
\hline Blepharocalyx salicifolius (Kunth.) O.Berg & 0,46 & 0,46 & CEL & - & - & - & 0,20 & 2,36 & 0,0045 \\
\hline Myrciaria delicatula (DC.) O.Berg & 0,38 & 0,50 & CTS & - & 6,94 & 1 & 0,16 & 7,46 & 0,0041 \\
\hline Schinus terebinthifolius Raddi & 0,38 & 0,25 & CEL & 6,94 & - & -1 & 2,19 & 0,12 & $-0,0047$ \\
\hline Mimosa scabrella Benth. & 0,37 & 0,89 & $\mathrm{P}$ & - & 38,52 & 12 & - & 15,11 & 0,0978 \\
\hline Dalbergia frutescens (Vell.) Britton & 0,36 & 0,39 & CEL & 15,91 & 9,64 & -1 & 20,78 & 7,22 & $-0,0183$ \\
\hline Inga lentiscifolia Benth. & 0,32 & 0,33 & CEL & - & - & - & - & 5,31 & 0,0087 \\
\hline Myrcianthes gigantea (D.Legrand) D. Legrand & 0,30 & 0,31 & CEL & - & - & - & - & 0,72 & 0,0044 \\
\hline Lamanonia ternata Vell. & 0,20 & 0,20 & CEL & - & - & - & - & 0,37 & 0,0009 \\
\hline Sloanea hirsuta (Schott) Planch. ex Benth. & 0,17 & 0,18 & CTS & - & - & - & - & 3,50 & 0,0068 \\
\hline Ilex microdonta Reissek & 0,16 & 0,16 & CEL & - & - & - & 1,94 & - & $-0,0023$ \\
\hline Myrceugenia sp. & 0,16 & 0,15 & - & - & - & - & 1,69 & - & $-0,0019$ \\
\hline Cabralea canjerana (Vell.) Mart. & 0,15 & 0,16 & CEL & - & - & - & - & 7,60 & 0,0087 \\
\hline Ilex dumosa Reissek & 0,15 & 0,16 & CEL & - & - & - & - & 1,68 & 0,0019 \\
\hline Symplocos uniflora (Pohl) Benth. & 0,14 & 0,14 & CEL & - & - & - & - & 3,21 & 0,0023 \\
\hline Cestrum intermedium Sendtn. & 0,13 & 0,13 & $\mathrm{P}$ & - & - & - & - & 6,23 & 0,0013 \\
\hline Cinnamomum amoenum (Nees \& Mart.) Kosterm. & 0,13 & 0,13 & CEL & - & - & - & - & 1,80 & 0,0004 \\
\hline Citronella paniculata (Mart.) R.A.Howard & 0,13 & - & CEL & 100,0 & - & -1 & 100,0 & - & $-0,0106$ \\
\hline Ilex paraguariensis A.St.-Hil. & 0,13 & 0,13 & CTS & - & - & - & - & 3,74 & 0,0010 \\
\hline Ligustrum lucidum W.T.Aiton & 0,13 & 0,13 & CEL & - & - & - & - & 17,23 & 0,0050 \\
\hline Myrceugenia euosma (O.Berg) D.Legrand & 0,13 & 0,29 & CEL & - & 24,02 & 2 & - & 28,24 & 0,0093 \\
\hline Oreopanax fulvus Marchal & 0,13 & 0,13 & CEL & - & - & - & - & 2,67 & 0,0007 \\
\hline Pinus taeda $\mathrm{L}$. & 0,13 & 0,68 & $\mathrm{P}$ & - & 40,54 & 7 & - & 50,04 & 0,0503 \\
\hline Piptocarpha angustifolia Dusén ex Malme & 0,13 & 0,42 & $\mathrm{P}$ & - & 24,02 & 2 & - & 41,75 & 0,0382 \\
\hline Solanum mauritianum Scop. & 0,13 & - & $\mathrm{P}$ & 100,0 & - & -1 & 100,0 & - & $-0,0034$ \\
\hline Solanum variabile Mart. & 0,13 & - & $\mathrm{P}$ & 100,0 & - & -1 & 100,0 & - & $-0,0072$ \\
\hline Eugenia hiemalis Cambess. & 0,12 & 0,12 & CEL & - & - & - & - & 1,48 & 0,0001 \\
\hline Baccharis semiserrata DC. & - & 0,12 & $\mathrm{P}$ & - & 100,0 & 1 & - & 100,0 & 0,0031 \\
\hline Baccharis uncinella DC. & - & 0,26 & $\mathrm{P}$ & - & 100,0 & 2 & - & 100,0 & 0,0113 \\
\hline Celtis iguanaea (Jacq.) Sarg. & - & 0,26 & $\mathrm{P}$ & - & 100,0 & 2 & - & 100,0 & 0,0131 \\
\hline Miconia cinerascens Miq. & - & 0,12 & $\mathrm{P}$ & - & 100,0 & 1 & - & 100,0 & 0,0024 \\
\hline Total & 100 & 100 & - & 3,13 & 3,10 & -1 & 3,40 & 2,14 & $-1,3962$ \\
\hline
\end{tabular}

Em que: $\mathrm{VI}_{2011}=$ valor de importância em 2011 (\%); $\mathrm{VI}_{2015}=$ valor de importância em 2015 (\%); GE = grupo ecológico $(\mathrm{CEL}=$ clímax exigente em luz; $\mathrm{CTS}=$ clímax tolerante ao sombreamento e $\mathrm{P}=$ pioneira $) ; \mathrm{T}_{\text {mort }}=$ taxa de mortalidade $\left(\%\right.$.ano $\left.{ }^{-1}\right) ; \mathrm{T}_{\mathrm{rec}}=$ taxa de recrutamento $\left(\%\right.$.ano $\left.{ }^{-1}\right) ; \mathrm{D}_{\mathrm{NI}}=$ diferença de número de indivíduos entre os inventários; $\mathrm{T}_{\text {per }}=$ taxa de perda em área basal $\left(\%\right.$.ano $\left.{ }^{-1}\right) ; \mathrm{T}_{\text {gan }}=$ taxa de ganho em área basal $\left(\%\right.$.ano $\left.{ }^{-1}\right) ; \mathrm{D}_{\mathrm{AB}}=$ diferença em área basal entre os inventários $\left(\mathrm{m}^{2}\right)$. 
por apenas um indivíduo em 2011, e pela entrada de Baccharis semiserrata, Baccharis uncinella, Celtis iguanaea e Miconia cinerascens em 2015, também representados por poucos indivíduos (um ou dois). Tanto as espécies do gênero Solanum que saíram, como todas as espécies que entraram em 2015, eram pioneiras, indicando a elevada substituição florística deste grupo de espécies, devido ao seu ciclo de vida mais acelerado.

A família Myrtaceae foi a mais representativa no estudo, com 18 espécies amostradas. A elevada riqueza de Myrtaceae é um padrão recorrente em fragmentos de Floresta Ombrófila Mista ou em ecótonos com influência de FOM, não apenas na região do Planalto Sul Catarinense (KLAUBERG et al., 2010; HIGUCHI et al., 2012a; 2012b; SILVA et al., 2012; HIGUCHI et al., 2013), mas no sul do Brasil (JARENKOW; BATISTA, 1987; IURK et al. 2009). Em segundo lugar de riqueza de espécies vieram as famílias Aquifoliaceae, Asteraceae, Lauraceae, Salicaceae e Sapindaceae, todas com quatro espécies, sendo que Asteraceae obteve seis espécies em 2015, com a entrada das duas espécies de Baccharis. A contaminação da área amostrada foi representada por Pinus taeda, espécie pioneira pertencente à família Pinaceae e Ligustrum lucidum, espécie clímax exigente em luz pertencente à família Oleaceae.

As três espécies de maior Valor de Importância (VI) em ambos os períodos foram Casearia decandra (8,73\% em 2011 e 9,35\% em 2015, família Salicaceae), Myrcia hatschbachii (7,15\% em 2011 e 7,12\% em 2015, família Myrtaceae) e Calyptranthes concinna (5,84\% em 2011 e 5,73\% em 2015, família Myrtaceae). Klauberg et al. (2010) amostraram outro trecho da floresta nativa no PARNAMUL e também encontraram alto valor de VI para Casearia decandra, espécie de pequeno porte e tolerante ao sombreamento, confirmando o padrão encontrado e a relevância da espécie como elemento do sub-bosque da Floresta Ombrófila Mista (KOZERA et al., 2006).

Em 2011, a maior parte das espécies $(71,23 \%)$ foi classificada como climácicas exigentes em luz, seguido por climácicas tolerantes ao sombreamento $(15,07 \%)$ e pioneiras $(12,33 \%)$. Em 2015, as CEL permaneceram como as espécies mais representativas na comunidade $(68,92 \%)$, porém, as pioneiras e CTS se equivaleram (14,86\%). Apenas uma espécie não foi classificada quanto à guilda de regeneração, pelo fato de sua determinação botânica ter ocorrido apenas ao nível de gênero (Myrceugenia sp., que representou $1,37 \%$ e 1,35\% em participação nos anos de 2011 e 2015, respectivamente). O fato das três espécies de maior importância relativa (Casearia decandra, Myrcia hatschbachii e Calyptranthes concinna) serem clímax tolerante ao sombreamento e do maior número de espécie pertencer ao grupo das climácicas exigentes em luz, sugere que o trecho da floresta nativa amostrado, em sua maior área, encontra-se em um estádio intermediário a avançado de sucessão ecológica, conforme já observado por Dalla Rosa et al. (2015) em estudo com guildas de regeneração em diferentes distâncias da borda nessa mesma área. No estudo de Klauberg et al. (2010), também foi verificado o predomínio de espécies climácicas exigentes por luz, classificadas por eles como secundárias. Porém, o aumento da representatividade de espécies pioneiras demonstra a relevância dos trechos em início de estágio de sucessão para a dinâmica florestal na área do presente estudo. Dessa forma, considerando que a floresta possui trechos em diferentes estágios sucessionais, sua susceptibilidade à contaminação biológica é dependente, também, do potencial das espécies exóticas invasoras de colonizar e de se estabelecer em diferentes fases de desenvolvimento da vegetação, de forma que a invasão representa um processo influenciado pela presença de fontes de propágulos e pela autoecologia das espécies. Estudos recentes têm demonstrado que espécies exóticas invasoras têm o potencial de colonizar e de se estabelecer em diferentes fases de desenvolvimento da vegetação (FLORY; CLAY, 2009; PADILHA et al., 2015; TNG et al., 2015), dependendo do grupo sucessional que as espécies estão inseridas.

Em relação às taxas demográficas da comunidade, observou-se a estabilidade no número de árvores, com a redução de um indivíduo, devido às taxas de mortalidade $\left(3,13 \%\right.$.ano $\left.{ }^{-1}\right)$ e recrutamento $\left(3,10 \%\right.$.ano $\left.{ }^{-1}\right)$ terem sido semelhantes; e uma instabilidade da área basal, com a redução de 1,3962 $\mathrm{m}^{2}$, uma vez que a taxa de perda em área basal $\left(3,40 \%\right.$. ano $\left.\mathrm{o}^{-1}\right)$ foi superior à de ganho $\left(2,14 \%\right.$. ano $\left.\mathrm{o}^{-1}\right)$. Este padrão sugere que durante o período ocorreu a mortalidade de árvores de grande porte, que foram substituídas por regenerantes, de menor porte.

A dinâmica das populações foi bastante variável. Casearia decandra, de maior VI, obteve um balanço positivo, com maior recrutamento $\left(3,99 \%\right.$. ano $\left.{ }^{-1}\right)$ do que mortalidade $\left(2,10 \%\right.$.ano $\left.{ }^{-1}\right)$, o que resultou em um aumento de 13 indivíduos na população e que também contribuiu para a maior taxa de ganho em área basal $\left(3,88 \%\right.$.ano $\left.{ }^{-1}\right)$ do que de perda $\left(1,56 \%\right.$.ano $\left.{ }^{-1}\right)$, resultando em aumento de $0,1153 \mathrm{~m}^{2}$. Porém, boa 
parte das populações apresentou perda em área basal, como Myrcia hatschbachii que, apesar de apresentar as mesmas taxas de mortalidade e recrutamento $\left(2,32 \%\right.$.ano $\left.0^{-1}\right)$ e de não apresentar mudança no número de indivíduos entre os anos, apresentou maior taxa de perda $\left(2,97 \%\right.$.ano $\left.{ }^{-1}\right)$ do que de ganho $\left(1,65 \%\right.$.ano $\left.{ }^{-1}\right)$ em área basal, devido à mortalidade de indivíduos de maior porte e recrutamento de indivíduos menores, o que resultou em perda de $-0,1307 \mathrm{~m}^{2}$ em área basal. Padrão semelhante foi encontrado para Myrsine coriacea que, apesar do ganho de quatro indivíduos devido à maior taxa de recrutamento $\left(11,99 \%\right.$.ano $\left.{ }^{-1}\right)$ do que de mortalidade $\left(4,89 \%\right.$.ano $\left.{ }^{-1}\right)$, apresentou redução em área basal $\left(-0,0420 \mathrm{~m}^{2}\right)$ devido às perdas dos indivíduos de maior porte. Já Calyptranthes concinna apresentou resultado bastante distinto, com maior mortalidade $\left(2,67 \%\right.$.ano $\left.{ }^{-1}\right)$ do que recrutamento $\left(0,35 \%\right.$. ano $\left.{ }^{-1}\right)$, resultando na perda de sete indivíduos na população, contudo, ao contrário do esperado, houve maior ganho $\left(2,22 \%\right.$.ano $\left.{ }^{-1}\right)$ do que perda $\left(1,69 \%\right.$.ano $\left.{ }^{-1}\right)$ em área basal, resultando em balanço positivo de $0,0366 \mathrm{~m}^{2}$ na população devido ao crescimento das sobreviventes ser maior do que a área basal dos indivíduos que morreram. Campomanesia xanthocapra, ao contrário dos outros casos, não apresentou indivíduos recrutas nem mortos, mesmo assim seu crescimento foi variável, apresentando perda $\left(0,59 \%\right.$.ano $\left.{ }^{-1}\right)$ e ganho $\left(0,60 \%\right.$. ano $\left.{ }^{-1}\right)$ em área basal. A perda pode ter ocorrido devido à mortalidade de caules bifurcados ou pelo próprio processo de senescência da árvore que pode resultar em menor diâmetro, e o ganho ocorreu devido ao crescimento das sobreviventes.

\section{Quantificação do nível de contaminação biológica}

As espécies invasoras tiveram baixa representatividade na comunidade, considerando todos os atributos vegetacionais (riqueza, abundância e área basal) e anos avaliados (Tabela 2). Guidini et al. (2014) avaliaram, nas mesmas parcelas, o componente regenerativo (DAP $<5 \mathrm{~cm}$ e altura $>10 \mathrm{~cm}$ ) e também registraram baixo e lento potencial de invasão. Porém, ressalta-se que os baixos valores dos indicadores não devem ser interpretados como uma sugestão de que a invasão biológica não representa um problema na área de estudo. De acordo com Sakai et al. (2001), a invasão biológica ocorre em etapas, sendo que a baixa participação em uma comunidade pode representar uma fase lag, que ocorre entre o estabelecimento inicial em uma área e o posterior rápido crescimento e expansão populacional.

TABELA 2: Indicadores do nível de invasão biológica por espécies arbóreas exóticas em um fragmento de Floresta Ombrófila Mista Montana, próximo a plantios comerciais de Pinus taeda em Lages - SC.

TABLE 2: Biological invasion indicators by exotic tree species in an Araucaria Forest fragment near Pinus taeda commercial plantations in Lages, SC state.

\begin{tabular}{ccccccc}
\hline & $\mathrm{R}_{2011}$ & $\mathrm{R}_{2015}$ & $\mathrm{~A}_{2011}$ & $\mathrm{~A}_{2015}$ & $\mathrm{AB}_{2011}$ & $\mathrm{AB}_{2015}$ \\
\hline Participação na comunidade & $2,74 \%$ & $2,70 \%$ & $0,20 \%$ & $0,45 \%$ & $0,03 \%$ & $0,24 \%$ \\
Participação entre as pioneiras & $11,11 \%$ & $9,09 \%$ & $2,70 \%$ & $12,31 \%$ & $0,25 \%$ & $3,31 \%$ \\
Participação entre as CEL & $1,92 \%$ & $1,96 \%$ & $0,17 \%$ & $0,18 \%$ & $0,02 \%$ & $0,05 \%$ \\
\hline
\end{tabular}

Em que: Os valores de riqueza (R), abundância (A) e área basal (AB) são relativos ao grupo das espécies invasoras, no caso da comunidade, ao Pinus taeda, no caso das pioneiras e ao Ligustrum lucidum, no caso das climácicas exigentes em luz (CEL).

Quando a participação das espécies exóticas é analisada por grupos ecológicos, observa-se um padrão distinto, com Pinus taeda apresentando uma maior representatividade na riqueza das espécies classificadas como pioneiras, $11,1 \%$ e $9,09 \%$ nos anos de 2011 e 2015, respectivamente. Ainda, entre os anos avaliados, destaca-se um aumento da relevância de Pinus taeda em relação aos aspectos estruturais no grupo das pioneiras, passando de 2,70\% para $12,31 \%$ da abundância e de $0,25 \%$ para $3,31 \%$ da área basal. Por outro lado, Ligustrum lucidum, que se comporta como clímax exigente em luz na região, apresentou uma participação inexpressiva entre as espécies CEL, para todos os aspectos ecológicos considerados, em ambos os anos. Assim, fica evidenciado que na área de estudo, o grupo das pioneiras foi o mais afetado pelo processo de invasão, reforçando a importância da necessidade de se considerar o processo de invasão nos diferentes grupos ecológicos. 
No caso da invasão por Pinus taeda, apesar do contato próximo com o plantio de pinus, o baixo valor de importância considerando toda a comunidade se deve ao fato desta exigir altos valores de incidência de radiação solar, o que dificulta sua regeneração natural em fragmentos em estágio mais avançado de sucessão e sem corte seletivo atual, como é o caso do remanescente estudado. Nestas circunstâncias, o desenvolvimento de espécies pioneiras ocorre apenas em áreas com maior disponibilidade de luz, como clareiras e bordas. Segundo Ziller e Galvão (2002), espécies do gênero Pinus se desenvolvem muito bem em áreas abertas, cuja incidência de raios solares é maior. Os mesmos autores, estudando a contaminação biológica por Pinus elliottii e Pinus taeda no Paraná, citam a resistência de formações florestais a essas espécies. Esse fato é confirmado pela localidade das árvores de pinus estabelecidas no presente estudo, sendo que cinco indivíduos foram amostrados em uma única parcela, que foi alocada em uma área de clareira. Porém, considerando o grupo ecológico das pioneiras, Pinus taeda teve uma participação relativamente expressiva, desempenhando, desta forma, um papel relevante no funcionamento na comunidade como oportunista e colonizadora de áreas abertas, o que pode trazer consequências futuras para a comunidade, considerando que a floresta está sujeita, periodicamente, à abertura de clareiras e posterior colonização por espécies de início de sucessão ecológica.

Para Ligustrum lucidum, uma espécie que pode ser classificada como CEL - considerando observações de campo e que Guidini et al. (2014) encontraram sua ocorrência predominantemente com espécies pertencentes a esse grupo ecológico -, foi encontrado somente um indivíduo na parcela 4, a $60 \mathrm{~m}$ da borda. Possivelmente, o baixo número de invasores de ligustro se deve ao fato de não existir uma fonte de propágulos muito próxima ao remanescente estudado. Em fragmentos mais próximos à área urbana da cidade, onde essa espécie é cultivada na arborização urbana, normalmente se encontra alto número de invasores, como demonstrado no estudo de Guidini et al. (2014) em outro fragmento estudado. Segundo o Instituto Horus (2010), espécies desse gênero, como Ligustrum lucidum e Ligustrum japonicum Thunb., possuem alto potencial invasor.

De acordo com Santana e Encinas (2008), é importante considerar o potencial invasor das espécies em função de seu histórico em outros locais. No caso das espécies invasoras do presente estudo, ambas possuem alto potencial invasor de acordo com o Instituto Horus (2010), ressaltando a importância de seu monitoramento e manejo, especialmente em caso de algum distúrbio que ocasione a interrupção do dossel contínuo na floresta natural do parque, o que facilitaria o recrutamento do Pinus taeda. Como essa espécie invasora, com fonte de propágulos mais próxima à área de estudo, é exigente em luz, seria necessário um distúrbio natural (e.g. abertura de clareiras naturais pela queda de árvores) ou antrópico (e.g. corte seletivo) para que esta se disseminasse pela área. Segundo Zanchetta e Pinheiro (2007), a proximidade e a falta de uma vegetação com densidade suficiente entre a fonte de propágulos e as áreas invadidas fazem com que a dispersão seja eficaz no processo de invasão, podendo a dispersão ser bem-sucedida mesmo com ventos leves. Assim, como destacado anteriormente, a autoecologia das espécies invasoras e a presença de fontes de propágulos são fatores determinantes no processo de invasão.

Em relação à invasão ao longo do tempo, destaca-se que, enquanto no conjunto de espécies nativas, as taxas de mortalidade $\left(3,14 \%\right.$.ano $\left.{ }^{-1}\right)$ e de perda em área basal $\left(3,40 \%\right.$.ano $\left.{ }^{-1}\right)$ foram superiores às taxas de recrutamento $\left(2,89 \%\right.$. ano $\left.{ }^{-1}\right)$ e o ganho em área basal $\left(2,09 \%\right.$.ano $\left.{ }^{-1}\right)$, para as espécies exóticas observou-se expressiva taxa de recrutamento $\left(34,70 \%\right.$.ano $\left.{ }^{-1}\right)$ e ganho em área basal $\left(40,81 \%\right.$.ano $\left.0^{-1}\right)$, sem apresentar taxas de mortalidade e perdas, reforçando a tendência de aumento na importância das espécies invasoras (Tabela 3). Este aumento expressivo da importância de espécies exóticas, especialmente de Pinus taeda entre as espécies pioneiras, pode ser explicado por suas taxas demográficas em relação às espécies nativas pertencentes a este grupo ecológico. Enquanto $P$. taeda caracterizou-se por apresentar elevados valores de recrutamento $\left(40,54 \%\right.$.ano $\left.{ }^{-1}\right)$ e de ganho em área basal $\left(50,04 \%\right.$.ano $\left.{ }^{-1}\right)$, sem a ocorrência de mortalidade e perdas em área basal, as espécies pioneiras nativas, apesar de um balanço positivo para estas variáveis estruturais, apresentaram percentual menor de recrutamento $\left(15,54 \%\right.$.ano $\left.{ }^{-1}\right)$ e ganho em área basal $\left(6,20 \%\right.$.ano $\left.{ }^{-1}\right)$, além de apresentar também mortalidade $\left(5,26 \%\right.$.ano $\left.{ }^{-1}\right)$ e perdas em área basal $\left(2,91 \%\right.$.ano $\left.{ }^{-1}\right)$. De acordo com Theoharides e Duckes (2007), o processo de invasão é caracterizado por fases distintas, representadas pelo transporte, colonização, estabelecimento e espalhamento na paisagem. Como não foram amostrados indivíduos em fase reprodutiva, infere-se que $P$. taeda encontra-se em fase de colonização, a partir da importante fonte de propágulos representado pelo plantio comercial adjacente. Caso 
os indivíduos dessa espécie superem as resistências bióticas existentes e consigam se reproduzir no local, $P$. taeda poderá avançar para fases seguintes no processo de invasão, ocupando setores em início de estágio de sucessão, como, por exemplo, clareiras naturais. Assim, os resultados das taxas demográficas sugerem, em médio a longo prazo, a possibilidade de $P$. taeda aumentar sua importância entre as pioneiras, mediante a manutenção do plantio adjacente como fonte de propágulo e, ou, a capacidade dos indivíduos colonizadores entrarem em fase reprodutiva.

TABELA 3: Taxas demográficas, em \%.ano ${ }^{-1}$, para o conjunto de espécies arbóreas nativas e exóticas, considerando a comunidade e os grupos ecológicos, em um fragmento de Floresta Ombrófila Mista Montana, próximo a plantios comerciais de Pinus taeda em Lages - SC.

TABLE 3: Demographic rates, in $\%$. year ${ }^{-1}$, for native and exotic trees species, considering the community and ecological groups, in an Araucaria Forest fragment near Pinus taeda commercial plantations, in Lages, SC state.

\begin{tabular}{lcc}
\hline \multicolumn{1}{c}{ Comunidade } & Nativas & Exóticas \\
\hline Taxa de mortalidade & 3,14 & - \\
Taxa de recrutamento & 2,89 & 34,70 \\
Taxa de perda em área basal & 3,40 & - \\
Taxa de ganho em área basal $\quad$ Pioneiras & 2,09 & 40,81 \\
\multicolumn{1}{l}{ Taxa de mortalidade } & 5,26 & - \\
Taxa de recrutamento & 15,54 & 40,54 \\
Taxa de perda em área basal & 2,91 & - \\
Taxa de ganho em área basal & 6,20 & 50,04 \\
$\quad$ Clímax exigentes em luz & & \\
Taxa de mortalidade & 3,54 & - \\
Taxa de recrutamento & 2,16 & - \\
Taxa de perda em área basal & 3,76 & 17,23 \\
Taxa de ganho em área basal & 1,71 & \\
\hline
\end{tabular}

Em relação ao grupo das climácicas exigentes em luz, ficou evidenciado que Ligustrum lucidum, apesar de apresentar um expressivo aumento em área basal $\left(17,23 \%\right.$.ano $\left.{ }^{-1}\right)$, não apresentou recrutamento durante o período avaliado. Considerando que esta espécie já foi relatada como uma importante invasora em um remanescente florestal perturbado próximo da área de estudo (GUIDINI et al., 2014), infere-se que sua baixa expressão local se deve à ausência de uma importante fonte de propágulos, de forma que a mesma encontra-se em etapa inicial de colonização, de acordo com as fases de invasão propostas por Theoharides e Duckes (2007), sendo que seu estabelecimento dependerá de sua capacidade de superar as resistências bióticas para poder se reproduzir localmente.

\section{CONCLUSÕES}

Foi possível observar uma alta riqueza de espécies arbóreas nativas em um trecho de FOM em estágio avançado de sucessão no PARNAMAUL, próximo ao plantio de Pinus taeda. Houve invasão biológica nessa porção da floresta, com a ocorrência de duas espécies exóticas: Pinus taeda e Ligustrum lucidum. Considerando a comunidade como um todo, ambas tiveram baixos valores para os indicadores de invasão utilizados nos dois períodos avaliados. No entanto, a análise por grupos ecológicos indicou maior importância do Pinus taeda no grupo das pioneiras, sendo este o componente mais afetado pela invasão biológica, o que reforça a necessidade de análise considerando esses diferentes grupos. Ainda, as taxas demográficas sugerem que, a médio ou longo prazo, Pinus taeda poderá aumentar sua importância entre as pioneiras, caso exista a manutenção do plantio na proximidade e/ou os indivíduos que se regeneraram na área consigam entrar em fase reprodutiva, demonstrando que plantios comerciais dessa espécie podem 
representar uma fonte de contaminação em áreas naturais. Não deve ser descartada a possibilidade de que a baixa representatividade de Ligustrum lucidum reflita uma fase inicial de colonização, de forma que a mesma possa aumentar sua importância ao longo do tempo. Para inferências mais conclusivas, um monitoramento por um maior período de tempo se faz necessário, como, de fato, está sendo realizado na área de estudo, mas, considerando a inferência que ambas espécies se encontram ainda em processo de colonização, recomenda-se a remoção dos indivíduos de espécies invasoras já estabelecidos nos demais locais no fragmento.

\section{AGRADECIMENTOS}

Ao CNPq, pela concessão de bolsa de produtividade em pesquisa ao segundo e terceiro autores. À FAPESC, pelo apoio financeiro por meio do Edital PAP/UDESC.

\section{REFERÊNCIAS}

HYLOGENY GROUP. An update of the Angiosperm Phylogeny Group classification for the orders and families of flowering plants: APG III. Botanical Journal of the Linnean Society, London, v. 161, n. 2, p. 105-121, 2009.

BRASIL. Ministério da Agricultura e Reforma Agrária. Normais climatológicas 1961-1990. Brasília: Ministério da Agricultura e Reforma Agrária, 1992.

CATFORD, J. A. et al. Quantifying levels of biological invasion: towards the objective classification of invaded and invasible ecosystems. Global Change Biology, Hoboken, v. 18, n. 1, p. 44-62, 2012.

DALLA ROSA, A. et al. Diversidade e guildas de regeneração de espécies arbóreas na borda de uma floresta nativa em contato com plantio de pinus. Floresta, Curitiba, v. 45, n. 2, p. 273-280, 2015.

FALLEIROS, R. M. et al. Invasão e manejo de Pinus taeda em campos de altitude do Parque Estadual do Pico Paraná, Paraná, Brasil. Floresta, Curitiba, v. 41, n. 1, p. 123-134, 2011.

FLORY, S. L.; CLAY, K. Effects of roads and forest successional age on experimental plant invasions.

Biological Conservation, Amsterdam, v. 142, n. 11, p. 2531-2537, 2009.

GENOVESI, P. Eradications of invasive alien species in Europe: a review. Biological Invasions, Nova York, v. 7, p. 127-133, 2005.

GUIDINI, A. L. et al. Invasão por espécies arbóreas exóticas em remanescentes florestais no Planalto Sul Catarinense. Revista Árvore, Viçosa, MG, v. 38, n. 3, p. 469-478, 2014.

HIGUCHI, P. et al. Influência de variáveis ambientais sobre o padrão estrutural e florístico do componente arbóreo, em um fragmento de Floresta Ombrófila Mista Montana em Lages, SC. Ciência Florestal, Santa Maria, v. 22, n. 1, p. 79-90, 2012a.

HIGUCHI, P. et al. Floristic composition and phytogeography of the tree component of Araucaria Forest fragments in southern Brazil. Brazilian Journal of Botany, São Paulo, v. 35, n. 2, p. 145-157, 2012b.

HIGUCHI, P. et al. Florística e estrutura do componente arbóreo e análise ambiental de um fragmento de Floresta Ombrófila Mista Alto-montana no município de Painel, SC. Ciência Florestal, Santa Maria, v. 23, n. 1, p. 153-164, 2013.

IBGE. Manual técnico da vegetação brasileira. Rio de Janeiro: Fundação Instituto Brasileiro de Geografia e Estatística, 2012.271 p.

INSTITUTO HÓRUS. Instituto Hórus de desenvolvimento e conservação ambiental. Disponível em: $<\mathrm{http}$ ://www.institutohorus.org.br/> Acesso em: $17 \mathrm{dez} .2010$.

IURK, M. C. et al. Levantamento florístico de um fragmento de Floresta Ombrófila Mista Aluvial do Rio Iguaçú, município de Palmeira (PR). Floresta, Curitiba, v. 39, n. 3, p. 605-617, 2009.

JARENKOW, J. A.; BAPTISTA, L. R. M. Composição florística e estrutura da mata com araucária na Estação Ecológica de Aracuri, Esmeralda, Rio Grande do Sul. Napaea, Porto Alegre, v. 3, p. 9-18, 1987.

KLAUBERG, C. et al. Florística e estrutura de um fragmento de Floresta Ombrófila Mista no Planalto Catarinense. Biotemas, Florianópolis, v. 23, n. 1, p. 35-47, 2010.

KOZERA, C. et al. Fitossociologia do componente arbóreo de um fragmento de Floresta Ombrófila Mista Montana, Curitiba, PR, BR. Floresta, Curitiba, v. 36, n. 2, p. 225-237, 2006. 
LEYSER, G. et al. Regeneração de espécies arbóreas e relações com o componente adulto em uma floresta estacional no vale do rio Uruguai, Brasil. Acta Botanica Brasilica, Feira de Santana, v. 26, n. 1, p. 74-83, 2012.

LIEBERMAN, D. et al. Mortality patterns and stand turnover rates in a wet tropical forest in Costa Rica. Journal of Ecology, Hoboken, v. 73, n. 3, p. 915-924, 1985.

LINDENMAIER, D. S.; BUDKE, J. C. Florística, diversidade e distribuição espacial das espécies arbóreas em uma floresta estacional na bacia do rio Jacuí, Sul do Brasil. Pesquisas Botânica, São Leopoldo, v. 57, p. 193-216, 2006.

MACK, R. N. et al. Biotic invasions: causes, epidemiology, global consequences and control. Issues in Ecology, Washington, v. 5, p. 1-20, 2000.

MORETTO, S. P.; NODARI, E. S. Parque Ecológico João José Theodoro da Costa Neto: conservação da floresta em Lages. In: CONGRESSO INTERNACIONAL DE HISTÓRIA, 4., Maringá. Anais... Maringá: Universidade Estadual de Maringá, 2009. p. 4001-4010.

MUELLER-DOMBOIS, D.; ELLENBERG, H. Aims and of vegetation ecology. New York: John Wiley \& Sons, 1974. $547 \mathrm{p}$.

OLIVEIRAFILHO, A. T. et al. Effects of soils and topography on the distribution of tree species in a tropical riverine forest in south-eastern Brazil. Journal of Tropical Ecology, Cambridge, v. 10, n. 4, p. 483-508, 1994.

PRIMACK, R. B. et al. Growth rates and population structure of Moraceae trees in Sarawak, East Malaysia. Ecology, Washington, v. 66, n. 2, p. 577-588, 1985.

PADILHA, D. L.; LOREGIAN, A. C.; BUDKE, J. C. Forest fragmentation does not matter to invasions by Hoveniadulcis. Biodiversity and Conservation, Nova York, v. 24, n. 9, p. 2293-2304, 2015.

REITZ, R. Flora ilustrada catarinense. [s. 1.]: Herbario Barbosa Rodrigues, 1970.

SAKAI, A. K. et al. The population of invasive species. Annual Review of Ecology and Systematics, Palo Alto, v. 32, p. 305-332, 2001.

SANTANA, O. A.; ENCINAS, J. I. Levantamento de espécies arbóreas e o seu impacto nas espécies nativas em áreas adjacentes a depósitos de resíduos domiciliares. Revista Biotemas, Florianópolis, v. 21, n. 4 , p. 29-38, 2008.

SHEIL, D.; MAY, R. M. Mortality and recruitment rate evaluations in heterogeneous tropical forests. Journal of Ecology, Hoboken, v. 84, n. 1, p. 91-100, 1996.

SILVA, A. C. et al. Relações florísticas e fitossociologia de uma Floresta Ombrófila Mista Montana secundária em Lages, Santa Catarina. Ciência Florestal, Santa Maria, v. 22, n. 1, p. 193-206, 2012.

SILVA, A. C. et al. Caracterização fitossociológica e fitogeográfica de um trecho de floresta ciliar em Alfredo Wagner, SC, como subsídio para restauração ecológica. Ciência Florestal, Santa Maria, v. 23, n. 4, p. 579-593, 2013.

SOBRAL, M. E. G et al. Flora arbórea e arborescente do Rio Grande do Sul, Brasil. [s. 1.]: RiMa, 2006. SWAINE, M. D.; WHITMORE, T. C. On the definition of ecological species groups in tropical rain forest. Vegetatio, Nova York, v. 75, p. 81-86, 1988.

THEOHARIDES, K. A.; DUKES, J. S. Plant invasion across space and time: factors affecting nonindigenous species success during four stages of invasion. New Phytologist, Hoboken, v. 176, n. 2, p. 256-273, 2007. TNG, D. Y. P. et al. Characteristics of the Psidium cattleianum invasion of secondary rainforests. Austral Ecology, Hoboken, 2015 (on line first).

WESTBROOKS, R. Invasive plants, changing the landscape of America: fact book. Washington: Federal Interagency Committee for the Management of Noxious and Exotic Weeds, 1998. 107 p.

ZANCHETTA, D.; DINIZ, F. V. Estudo da contaminação biológica por Pinus spp. em três diferentes áreas na estação ecológica de Itirapina (SP, Brasil). Revista do Instituto Florestal, São Paulo, v. 18, p. 1-14, dez. 2006.

ZANCHETTA, D.; PINHEIRO, L. S. Análise biofísica dos processos envolvidos na invasão biológica de sementes de Pinus elliottii na estação ecológica de Itirapina-SP e alternativas de manejo. Climatologia e Estudos da Paisagem, Rio Claro, v. 2. n. 1, p. 72-90, 2007.

ZILLER, S. R.; GALVÃO, F. A degradação da estepe gramíneo-lenhosa no Paraná por contaminação biológica de Pinus elliottii e Pinus taeda. Floresta, Curitiba, v. 32, n. 1, p. 42-47, 2002. 